\title{
CONSUMO, COLECIONISMO E IDENIIDADE DOS BIBLIÓFILOS: UMA EINOGRAFIA EM DOIS SEBOS DE PORTO ALEGRE
}

\author{
Neusa Rolita Cavedon \\ Universidade Federal do Rio Grande do Sul - Brasil \\ Rodrigo Bisognin Castilhos \\ Faculdade de Integração do Ensino Superior do Cone Sul - Brasil \\ Lívia Donida Biasotto* \\ Universidade Federal do Rio Grande do Sul - Brasil \\ Indira Nahomi Caballero** \\ Museu Nacional/Universidade Federal do Rio de Janeiro - Brasil \\ Fabiana de Lima Stefanowski*** \\ Universidade Federal do Rio Grande do Sul - Brasil
}

Resumo: No presente artigo, buscamos desvendar o comportamento de consumo dos colecionadores de livros. Por meio do método etnográfico, percorremos o universo dos bibliófilos que circulam por dois sebos de Porto Alegre. O trabalho de campo revelou aspectos que extrapolam a visão funcionalista utilitária da aquisição de bens, evidenciando sociabilidades e reações emocionais ligadas ao consumo. Os referenciais de comportamento do consumidor e da antropologia do consumo nos permitiram acessar algumas particularidades dos bibliófilos, que incluem sociabilidades masculinas, consumo obsessivo, construção e reforço de uma identidade por meio do consumo. A principal contribuição do estudo reside na análise de um universo consumidor com características extremas, o que provê subsídios para a compreensão de alguns elementos do consumo na sociedade contemporânea, notadamente no que tange às propriedades simbólicas dos bens e os processos de

\footnotetext{
* Graduanda em Administração.

** Mestranda em Antropologia Social.

*** Graduanda em Ciências Sociais.
} 
apropriação e personalização das mercadorias quando da sua passagem do domínio da produção para o domínio do consumo.

Palavras-chave: colecionismo, consumo, etnografia, identidade.

Abstract: Our paper aims to study the behavior of consumption of book collectors. Through ethnography we investigate the world of the bibliophiles that frequent two second-hand bookstores in the city of Porto Alegre. The fieldwork has revealed some aspects that go beyond a utilitarian approach of goods acquisition and usage. Our analysis is based on previous works in Consumer Behavior and Anthropology of Consumption. This framework has permitted us to access a universe of consumption, which include male sociability, obsessive consumption, and the building of an identity through the consumption. The main contribution of this paper lies in the analysis of one extreme way of consumption, which can help us to understand some aspects of consumption in contemporary society, especially the symbolic proprieties of goods and the process of appropriation of goods in their moving from production to consumption.

Keywords: collectionism, consumption, ethnography, identity.

\section{Introduç̃o}

Dentre os diferentes consumidores de produtos culturais, alguns têm nos despertado especial atenção. Trata-se dos consumidores de livros usados, mais especificamente os bibliófilos. A natureza da relação desses indivíduos com livreiros e livros nos parece extremamente particular e interessante, sendo digna de um olhar mais atento por parte daqueles que buscam entender as peculiaridades atinentes ao comportamento do consumidor. Sendo assim, este artigo busca identificar as características desses consumidores e sua relação com os livros e com os espaços comerciais por onde esses objetos circulam: os sebos de Porto Alegre.

Inicialmente, cumpre esclarecer como o objeto de consumo, o livro, costuma ser definido. Para Rouveyre (2003, p. 15),

o livro é uma obra escrita por qualquer pessoa esclarecida sobre qualquer assunto de ciência, para instrução e entretenimento do leitor. Pode-se ainda definir um livro como sendo obra de um homem de letras, coligida para comunicar ao público e à posteridade tudo quanto o autor possa ter inventado, visto, experimentado e compilado, devendo constituir material considerável para encerrar-se num volume.

Horizontes Antropológicos, Porto Alegre, ano 13, n. 28, p. 345-371, jul./dez. 2007 
É esse objeto, o produto cultural que desperta tanto interesse aos bibliófilos. Mas quem são esses consumidores? Como eles se identificam e se diferenciam dos colecionadores de um modo geral? O bibliófilo não é um colecionador qualquer, ele tem uma lógica que norteia a sua coleção. "É preciso escolher com muito critério qual o gênero de livro que se quer colecionar. Nunca um bom colecionador deve ir comprando o que lhe agrada no momento" (Moraes, 2005, p. 20). Mais que uma simples coleção, o bibliófilo possui um acervo que deve evidenciar um acúmulo de tempo, de energia, de dinheiro e de conhecimento intelectual, que assume as suas características e reforça a sua identidade social distinta.

O comportamento de consumo dos colecionadores, por sua vez, tem gerado uma profícua discussão no contexto americano, tanto em journals de marketing como de psicologia (Baker; Gentry, 1996; Belk et al., 1988; McIntosh; Schmeichel, 2004). Apesar da proeminência do tema no exterior, pouca ou nenhuma importância tem sido dada no contexto brasileiro para esse tipo de consumidor especial, cujas motivações extrapolam em muito a dimensão utilitária do consumo (Belk et al., 1988), sendo uma das formas de construção e expressão de identidade por meio da cultura material (McCracken, 2003).

Diante do exposto já dá para perceber que os consumidores bibliófilos possuem certos pressupostos que os identificam como uma categoria específica de compradores que para intitularem-se como tal devem seguir determinados preceitos. A rigor interessa compreender como se dá essa identificação e qual a relação desses consumidores com os proprietários de sebos. Cumpre verificar se a fidelização desses clientes se dá para com um determinado sebo ou se o bibliófilo, por nutrir um "amor aos livros”, não estabelece uma relação restritiva a um local de comercialização, mas, ao contrário, busca satisfazer o seu prazer de consumo indo a vários sebos, atrás do que nossos informantes resolveram denominar de "surpresa”, isto é, o encontro com obras raras, como o exemplar faltante para completar uma determinada coleção.

Para que o leitor possa compreender esse universo, organizamos o artigo primeiramente buscando aprofundar algumas teorizações concernentes à antropologia do consumo. Após, procuramos enfocar as teorizações acerca do comportamento de consumo e das características dos colecionadores e de suas coleções trazendo as contribuições da administração. A seguir, o método que orientou nossa coleta de dados é apresentado para, então, lançarmo-nos à apresentação dos contextos investigados, no caso, dois sebos sediados em Porto Alegre. Finalmente, nos envolvemos na discussão dos achados de campo, en- 
tremeando a descrição com o diálogo estabelecido entre as duas áreas de conhecimento que dão suporte teórico ao estudo.

\section{Antropologia do consumo}

Barbosa (2004) procurou identificar e distinguir os autores que discutem a cultura do consumo daqueles que estudam a sociedade do consumo. Dentre os primeiros, teríamos Jean Baudrillard, autor paradigmático em se tratando de consumo de bens culturais, que teorizou acerca dos objetos não possuírem relevância tão-somente em razão de sua funcionalidade, mas serem considerados de acordo com a dimensão social e a significação a eles atribuída. Baudrillard (1972, p. 14) extrapola assim a visão do consumo fundada nas necessidades e na satisfação: "os objetos nunca se esgotam naquilo para que servem, e é nesse excesso de presença que ganham a sua significação de prestígio, que 'designam’ não já o mundo, mas o ser e a categoria social de seu possuidor”.

Para essa corrente teórica, a cultura do consumo estaria atrelada à sociedade pós-moderna, onde o consumo numa relação causal vincula-se ao estilo de vida, à reprodução social e à identidade, à autonomia da esfera cultural, ao signo e a vários aspectos considerados negativos, como a superficialidade e o materialismo.

Por seu turno, Douglas e Isherwood (2004) inserem-se dentre os autores que postulam a sociedade do consumo como descolada da sociedade pós-moderna. O foco desses teóricos centra-se na procura por compreender o que está em jogo quando da escolha dos bens e na noção do consumo como mediador das relações e práticas sociais.

Douglas e Isherwood (2004) evidenciam uma tendência nos estudos da área econômica no sentido de acreditar que as pessoas compram bens com dois ou três propósitos restritos: bem-estar material, bem-estar psíquico e exibição. Nesse caso, a Teoria Utilitarista Econômica não seria suficiente para responder o porquê das pessoas quererem bens, uma vez que não leva em conta que o consumo está inscrito nas normas socioculturais de uma determinada comunidade; isto é, ao invés de considerar que os bens sejam em primeiro lugar necessários à subsistência e à exibição competitiva, há que se supor sejam necessários para dar visibilidade e estabilidade às categorias culturais (Douglas; Isherwood, 2004).

Se a economia se fixa nessa vertente utilitarista, sendo capaz de criar modelos matemáticos para definir o comportamento do consumidor, na antropologia a propriedade física dos bens de consumo é considerada a partir da 
construção social que admite serem os bens capazes de aumentar a disponibilidade pessoal e o status social. Nessa perspectiva, sendo os bens dotados de significações sociais, eles são usados para delimitar as fronteiras entre grupos, para criar e demarcar diferenças ou o que existe de comum entre grupos de pessoas. O consumo deve ser visto então como um processo social (Douglas; Isherwood, 2004). A posse de um bem pode significar a inclusão ou exclusão em um determinado grupo, assim como pode significar um reconhecimento social.

Para Douglas e Isherwood (2004, p. 123-124), os bens são usados para marcar, no sentido de categorias de classificação, nesse caso, de uso público:

Os bens são dotados de valor pela concordância dos outros consumidores. Eles se reúnem para classificar eventos, mantendo julgamentos antigos ou alterandoos [...] cada indivíduo está no esquema de classificação cujas discriminações está ajudando a estabelecer [...] a espécie de mundo que criam em conjunto é construída a partir de mercadorias, escolhidas por sua adequação, para marcar eventos numa escala de graduação apropriada.

Sendo assim, as mercadorias passam a ser um elo de ligação (ponte) entre os indivíduos que as possuem ou que compartilham da mesma classificação do objeto, criando uma identidade. O consumo é um sistema de significação e a verdadeira necessidade que supre é a necessidade simbólica. Os bens são necessários para evidenciar e estabilizar categorias culturais e sua função essencial é fazer sentido, construindo um universo inteligível: "Os bens são neutros, seus usos são sociais, podem ser usados como cercas ou como pontes." (Douglas; Isherwood, 2004, p. 36).

De acordo com Featherstone (1997, p. 43, grifo nosso), "os bens artísticos e intelectuais são mercadorias encravadas cuja capacidade de circular no espaço social é limitada pelas qualidades sagradas a elas atribuídas”. Por possuírem tais qualidades, a circulação e o acesso a esses objetos ficam restritos à "alta cultura", delimitando fronteiras através do controle desses bens.

Featherstone (1995) argumenta que os bens materiais atuam como comunicadores e não como utilidades. Para Barbosa (2004), em Featherstone, a cultura do consumidor envolve dois aspectos: o prestígio e o lado simbólico. O primeiro requer capital cultural, dinheiro e tempo para que se granjeie status, já o segundo, implica satisfação pessoal. A satisfação pessoal talvez possa ser mais bem capturada se tivermos em conta a argumentação de Barbosa (2004), baseada em Campbell, de que a identidade do consumidor não se dá pela via daquilo que ele consome, mas sim em face da reação do consumidor frente aos 
bens e serviços adquiridos. Assim, Campbell (2001) postula que nós nos descobrimos em face da variedade de bens e serviços aos quais somos expostos, pois a nossa reação diante deles irá auxiliar no nosso autoconhecimento.

De acordo com Douglas e Isherwood (2004, p. 112): “os bens são acessórios rituais: o consumo é um processo ritual cuja função primária é dar sentido ao fluxo incompleto dos acontecimentos”. O consumidor pretende construir um universo inteligível mediante a sua escolha de bens usados para marcar um referencial de espaço e de tempo no ciclo de vida das pessoas e a variação de qualidade desses bens surge para diferenciar esses intervalos. Dentro do tempo e espaço disponíveis, o indivíduo usa o consumo para dizer coisas sobre si mesmo e talvez descobrir e revelar sua identidade (Douglas; Isherwood, 2004).

Barbosa (2004) destaca que, a partir da década de 1980, o consumo passa a ser compreendido como fulcral no que concerne ao processo de reprodução social de todas as sociedades, sendo, portanto, cultural em sua essência. A sociedade contemporânea privilegia o individualismo e em decorrência tem-se a liberdade de escolha sobre o que consumir, daí o estilo de vida ser determinante diante das alternativas.

Mas há que se ter em conta que a utilização da cultura material como forma de linguagem sempre existiu em todas as sociedades, portanto é preciso compreender o que subjaz ao ato de consumir, que significação lhe é possível atribuir tendo-se em conta os diferentes contextos e temporalidades (Barbosa, 2004). É isso que nos propomos a realizar ao descortinarmos o universo de consumo dos bibliófilos.

\section{Consumo, identidade e colecionismo}

A análise do comportamento dos bibliófilos nos leva à trilha teórica que considera a posse de bens como um elemento importante tanto na formulação quanto na expressão de identidades sociais (McCracken, 2003; Slater, 1997). Segundo Slater (1997), nas sociedades pós-tradicionais, a identidade deixa de ser atribuída pelo pertencimento a grupos de status e passa a ser construída a partir das escolhas individuais. Tal caminho passa pela compreensão de que os objetos carregam significados que são construídos culturalmente. Contudo, um objeto cultural não pode ser tomado individualmente, mas sim no seu contexto, ou seja, em sua função dentro da constelação de objetos que formam a teia de significados da qual ele faz parte (McCracken, 1989). Dessa forma, é a partir de uma série de objetos da cultura material e, cada vez mais, do uso que faze- 
mos deles (Bourdieu, 1979) que nos estabelecemos para a sociedade, para a nossa família e para nós mesmos.

Segundo Barbosa (2004), embora se possa dizer que por meio do consumo construímos identidades, na maioria das vezes elas são apenas confirmadas, uma vez que, por maior que seja a liberdade de escolha, ela está limitada ao contexto cultural em que se inscreve. Indo um pouco mais longe, porém, pode-se afirmar, igualmente, que o consumo reforça identidades.

Na teorização sobre identidade e consumo, Belk (1988) afirma que os indivíduos podem ser compreendidos a partir do exame das suas posses. O termo extended self está relacionado a tudo o que consideramos como nossos. Belk (1988) faz a distinção entre self (eu) e self estendido (meu). Segundo ele, diversos objetos podem ser apropriados ao self, ${ }^{1}$ tais como: posses pessoais; pessoas; lugares; posses de grupos. Ademais, na medida em que essas posses representam ou auxiliam na formação ou expressão de parte do self do consumidor, elas fazem parte do seu self estendido (Belk, 1988; Tian; Belk, 2005; Castilhos et al,, 2006). Isso instaura uma íntima relação entre consumo e identidade.

Mas o que dizer quando boa parte da identidade de um indivíduo se constrói, expressa ou é reforçada por meio do consumo de uma única categoria de objetos? Como compreender o comportamento dos colecionadores, mais especificamente, dos colecionadores de livros?

Por seus propósitos e pelo tempo, energia e dinheiro gastos em uma coleção, é natural que ela seja tida como mais importante na constituição do self de uma pessoa do que outros objetos de consumo isoladamente (Belk, 1988). Além disso, as coleções trazem consigo algumas características que fazem desse ato de consumo algo intenso e envolvente tanto para o colecionador quanto para aqueles que o cercam. Belk et al. (1988) realizaram o inventário dessas características, as quais devem nos auxiliar a compreender o comportamento dos bibliófilos: 1) as coleções raramente iniciam propositalmente, elas podem iniciar a partir de uma herança, mas normalmente evoluem sem a consciência dos colecionadores, que em um dado momento se "descobrem" como tal; 2) vício e compulsão fazem parte do colecionismo, o comportamento de busca por um item faltante é obsessivo, e normalmente estreita o horizonte de interesses do

\footnotetext{
1 Não há uma tradução apropriada para o termo self, alguns estudos o traduzem como “eu”. Por julgar que tal tradução implica perda de riqueza do termo, optamos por sua não tradução.
}

Horizontes Antropológicos, Porto Alegre, ano 13, n. 28, p. 345-371, jul./dez. 2007 
colecionador; 3) a aquisição se dá como arte ou ciência, há dois tipos de colecionadores, o primeiro é aquele que utiliza critérios afetivos para escolher os itens de sua coleção, enquanto o segundo emprega critérios cognitivos para escolher os objetos a serem incorporados. Tais itens devem auxiliá-lo a melhorar o seu conhecimento ao invés de aumentar a beleza da coleção. Os bibliófilos se incluem, preferencialmente, na segunda categoria; 4) o item incorporado é sacralizado, o ato de incorporação de um item à coleção é um ato de retirada do objeto do mundo impessoal e profano das commodities para o universo pessoal e socialmente significante da coleção; 5) coleções são uma extensão do self, como já foi dito, uma coleção acaba por moldar o self e o autoconceito de um colecionador; 6) a coleção tende à especialização, na medida em que a coleção avança, o colecionador passa a se tornar um connaisseur do assunto referente ao que está sendo colecionado; 7 ) a coleção gera problemas pós-morte para o colecionador e sua família, pois como parte do self, o colecionador busca fazer com que a sua coleção sobreviva à sua morte, de maneira a obter uma espécie de imortalidade, entretanto, algumas vezes a família não está interessada em continuar a coleção; 8) há um desejo e um medo simultâneo de completar a coleção, completar uma coleção é uma espécie de auto-realização. Contudo, como o sentido da coleção está na busca incessante, muitas vezes uma coleção completa pode significar um vazio para o colecionador.

Temos, então, no colecionador um tipo especial de consumidor. A coleção transcende de maneira completa o utilitarismo dos objetos, ela é uma experiência autotélica por excelência. Da mesma forma, por meio da coleção, o indivíduo não somente expressa, como constrói o seu self. Cumpre verificar como essas características do colecionismo se apresentam no caso dos bibliófilos de Porto Alegre.

\section{Método}

Quando se opta por fazer uso do método etnográfico em pesquisas atreladas ao campo administrativo há que se ter em conta a etiologia do referido método, de sorte a evitarmos equívocos decorrentes de uma possível banalização devido ao uso descolado do contexto de onde surgiu, ou seja, na antropologia (Jaime Jr., 2003). Uma das dificuldades enfrentadas, por quem não é da referida área, diz respeito à ampliação do espectro por parte dos antropólogos que não legitimam mais tão-somente a observação participante como sendo a téc- 
nica característica dos estudos etnográficos, as discussões já evoluíram para aquilo que é denominado de “encontro etnográfico”. Sobre isso, Clifford (1998, p. 43) afirma:

Torna-se necessário conceber a etnografia não como a experiência e a interpretação de uma "outra" realidade circunscrita, mas sim como uma negociação construtiva envolvendo pelo menos dois, e muitas vezes mais, sujeitos conscientes e politicamente significativos. Paradigmas de experiência e interpretação estão dando lugar a paradigmas discursivos de diálogo e polifonia.

Sendo o objetivo de tal método acessar "os significados simbólicos e culturais que estão subjacentes às ações humanas” (Rocha; Barros; Pereira, 2005, p.128), a sua utilização no marketing, especialmente, no campo do comportamento do consumidor é, no mínimo, promissora e provocativa. A emergência desse gênero de estudos no marketing se dá a partir do final da década de 1980 (Hill; Stamey, 1990; Schouten; McAlexander, 1995) no contexto americano. No Brasil, o método começa a ser considerado no marketing cerca de uma década mais tarde, primeiramente, com a emergência de artigos teóricos, discutindo os benefícios da utilização do método e das técnicas etnográficas (Rocha; Barros; Pereira, 2005) e, em seguida, com a aplicação em pesquisas empíricas ou de inspiração etnográfica (Matoso; Rocha, 2005).

Jaime Jr. (2003) destacou alguns pontos que devem ser levados em conta quando a pesquisa realizada possui uma interface com o mundo organizacional: 1) atentar para a tensão presente entre o familiar e o estranho; 2) minimizar a assimetria pesquisador-pesquisados mediante o diálogo com os interlocutores em campo; 3) desse diálogo, captar elementos que permitam identificar conflitos e ações cooperativas entre os interlocutores; 4) trabalhar a estada em campo desde o primeiro contato, procurando deixar claro que a presença em campo se fará de modo intensivo e discutir possíveis transtornos decorrentes dessa proximidade; 5) atentar para o fato de que em se tratando de organizações a distância entre pesquisador-pesquisado não é tão grande como a que porventura possa separar etnógrafo e pesquisados diante de diferenças raciais ou de nacionalidades; 6) privilegiar análises que levem em conta o referencial teórico existente no campo antropológico (o que não impede a utilização de outro referencial, quando a busca é pela interdisciplinaridade); 7) atentar para os aspectos históricos do contexto estudado; 8) a mesma lógica que norteia o trabalho de campo precisa ser acionada por ocasião da construção do relato 
etnográfico, ou seja, privilegiar o diálogo; 9) e, finalmente, ter ciência de que a interpretação do etnógrafo ao ser diferente daquela esposada pelo nativo não invalida uma ou outra, ambas são interpretações possíveis a partir de lentes diferentes.

A presente pesquisa iniciada em março de 2005 ainda se encontra em andamento e faz parte de um projeto maior que envolve a compreensão da cultura organizacional dos sebos e livrarias de Porto Alegre. Assim, mediante 0 uso do método etnográfico, pesquisamos o Beco dos Livros, onde foram feitas 31 inserções em campo, de março a agosto de 2005, observando diferentes momentos e acompanhando o dia-a-dia do estabelecimento. A aceitação de uma das pesquisadoras se deu de modo a permitir com que a mesma interagisse o tempo todo com os clientes, funcionários e proprietários, muitas vezes auxiliando os clientes na busca por algum exemplar nas prateleiras e em outras carregando livros de uma loja do Beco para outra.

Outro sebo objeto da pesquisa foi a Livraria Nova Roma. Três pesquisadoras mantiveram contato com o referido campo, porém, neste artigo, os dados apresentados e analisados dizem respeito àquela que permaneceu por mais tempo em interação com o campo, 19 encontros entre setembro a dezembro de 2005. A pesquisadora teve oportunidade de participar do processo de organização e higienização dos livros colocados à venda, bem como se envolver na atividade de inscrever uma marca d'água nos livros comercializados pela Nova Roma.

Essa convivência foi registrada nos diários de campo das respectivas pesquisadoras, que tiveram oportunidade de realizar entrevistas semi-estruturadas visando a minimizar possíveis dúvidas advindas da observação sistemática e participante e que requereram um maior aprofundamento.

\section{Beco dos Livros}

O prédio antigo pintado de azul, em frente à Casa de Cultura Mário Quintana e próximo a outros espaços culturais do bairro Centro, como o Museu de Arte do Rio Grande do Sul, o Memorial do Rio Grande do Sul e o Santander Cultural, nos faz perceber que a escolha geográfica vem ao encontro de um determinado público que provavelmente circula por esse entorno visando a usufruir bens e serviços culturais. Em especial, a Casa de Cultura Mário Quintana, local de inúmeras atividades culturais como cinema, exposições de artes plásticas dentre outras, deve atrair seus freqüentadores também para o sebo Beco dos Livros. Além desses clientes, o sebo chama a atenção de muitas pessoas 
que trabalham no bairro, como bancários e funcionários públicos, que nos intervalos de almoço costumam percorrer os estabelecimentos comerciais da região.

O Beco, como é chamado, é constituído de dois pisos; o primeiro piso é onde se encontram os livros disponibilizados em estantes aos consumidores, com destaque para os lembretes colocados nas prateleiras e nas paredes: "Os livros estão organizados por sobrenome do autor, por gentileza, mantenha a ordem”. O valor da obra é identificado por um número e uma letra. Uma tabela afixada permite conhecer o valor da letra que multiplicado pelo número constante na obra nos dá o preço do livro. Essa forma de atribuir preço aos livros foi mencionada por Moraes (2005, p. 36): “muitos livreiros não marcam o preço de venda nos livros em algarismos, mas em siglas formadas geralmente por letras”. Já o segundo piso da loja serve como depósito, e no futuro deverá se transformar em uma galeria de arte.

Dentre os proprietários Peter e Neiva, ela é quem se envolve de maneira mais intensa com a administração das lojas. Os dois mantêm a sociedade, uma vez que Peter reconhece o talento da ex-esposa para a venda, e Neiva, as aptidões de Peter para a compra de livros usados. A compra de bibliotecas por parte dos proprietários de sebo se dá através de contatos estabelecidos entre quem oferta (proprietário ou familiar em se tratando de alguém falecido) e o dono do sebo. É realizada uma avaliação para então proceder à negociação propriamente dita. A experiência do dia-a-dia fornece aos donos certo feeling para identificar os exemplares que terão boa procura por parte da clientela. Neiva e Peter parecem se complementar nas qualidades que são atribuídas aos bons livreiros: "o faro para descobrir, o talento para comprar barato e a fé em poder vender caro” (Moraes, 2005, p. 27).

\section{Livraria Nova Roma}

Localizada à rua General Câmara, número 428, a Livraria Nova Roma dista alguns metros da Biblioteca Pública do Estado, estando próxima ainda ao Teatro São Pedro, sendo, igualmente, circunscrita em um reduto cultural do Centro da capital gaúcha. O caixote de saldos na porta do estabelecimento configura-se como um grande chamariz para quem por ali transita.

A loja abarrotada de livros torna-se pequena, mas aconchegante. Uma mesa maior reúne os saldos de um real, a grande atração do local, não só pelo preço, mas pela renovação constante dos livros expostos. Há outra mesa menor que abriga ao seu redor os clientes que costumam trocar idéias com os 
proprietários do sebo. Cristaleiras contendo obras raras, o tic-tac dos cinco relógios antigos afixados nas paredes, sinos, canecos de chope e demais objetos de época decoram o ambiente.

Marquinhos, Carlinhos e André são os proprietários do estabelecimento. Alegres, estão sempre fazendo piada com os habitués do espaço. No dizer de André, o que torna a Livraria atrativa, em primeiro lugar, é o tratamento dado aos clientes, em segundo lugar o preço e em terceiro lugar a renovação constante do acervo mediante a compra de novos exemplares ou mesmo a retirada de determinados livros das estantes, passado algum tempo sem que tenham sido procurados. Existe uma preocupação muito grande em colocar o preço em todos os livros para evitar que o cliente se sinta lesado, pois corre entre os consumidores que muitos livreiros costumam atribuir um valor ao livro de acordo com o interesse ou a aparência do cliente, como coloca Moraes (2005, p. 36): "Muitos livreiros antiquários, nos países latinos, sobretudo, ainda acreditam nas virtudes do preço conforme a 'cara do freguês' e continuam a marcar seus livros com sinais cabalísticos”.

\section{Os bibliófilos e suas colecões}

Após uma convivência quase que diária nos sebos, acabamos por encontrar clientes que circulam pelos mesmos, mostrando-se fiéis aos livros e não aos livreiros; são os bibliófilos.

Dr. Aurélio é um desses clientes bibliófilos ${ }^{2}$ que tivemos oportunidade de encontrar no Beco dos Livros. Ele se diz "apaixonado por livros”. Freqüenta sebos há mais de 20 anos e optou por colecionar livros de literatura, história, biografias e memórias. Ao ler o livro de um determinado autor e dele se agradar, costuma ler a obra completa. Nos sebos, o psiquiatra Aurélio procura as primeiras edições, uma vez que nelas, segundo a sua ótica, a obra se apresenta nua e crua, sem modificações ou críticas. O prazer decorrente dessa busca pelas primeiras edições de livros antigos e consagrados, segundo o cliente, vai além do prazer da leitura, envolve o cheiro de fungo exalado pelo livro: "que cheirando tu percebe que o livro é datado do século passado ou mais velho ainda, aquelas páginas amarelas, a costura, a lombada, as palavras”. Com cer-

2 Os nomes dos clientes foram modificados de modo a preservar o seu anonimato. 
ca de quinze mil exemplares, sua residência acolhe parte do acervo até debaixo da cama. Trata-se de uma coleção horizontal, nos termos de Belk et al. (1988). Ademais, a declaração desse informante nos remete a uma dimensão importante da coleção, a contaminação, onde determinadas características do produto, nesse caso o cheiro, dão conta da sua trajetória, conferindo-lhe um caráter especial e simbólico (Belk et al., 1988). Portanto, é possível concluir que o bibliófilo se identifica e reconhece a sua coleção no cheiro de mofo, o que dá plenas condições ao exemplar em questão de fazer parte de seu acervo.

Moraes (2005, p. 21) faz referência a esse "amor pelos livros": "O prazer de colecionar, a emoção de encontrar um livro procurado há anos, a volúpia de completar as obras de um autor, é, para o milionário que paga uma fortuna por um livro, a mesma do pobretão que encontra num sebo o volume sonhado”. Mindlin é jornalista, advogado, livreiro, editor e empresário e, igualmente, um bibliófilo, também revelou sua emoção em relação ao contato com o livro raro:

Além do conteúdo, edição, encadernação, diagramação, tipografia, ilustração, ou papel, o livro exerce sobre mim uma atração física. Não me satisfaz ver um livro numa vitrine, sem poder pegá-lo. Minha tese é que a gente deve poder tocar naquilo que gosta, sentir objetos e pessoas [...] Quando, depois de anos e anos de procura, encontra-se um livro raro, o coração bate mais forte. Sente-se uma emoção grande, mas não se pode deixar que ela transpareça diante do livreiro. Por motivos óbvios... (Mindlin, 1997, p. 22-24).

Podemos acompanhar a narrativa do dr. Aurélio sobre a coleção na qual estava empenhado em conseguir exemplares, a obra de Lima Barreto. A sua escolha se deveu ao fato do autor ser um mulato contemporâneo de Machado de Assis que se dedicou não a relatar aspectos da aristocracia carioca, mas sim de pessoas populares como o personagem Policarpo Quaresma. Embora não tenha conseguido as primeiras edições, parecia satisfeito em ter comprado a terceira edição da Brasiliense, com capa dura, coberta por um invólucro de papel com uma ilustração de época. A compra ocorreu no sebo Martins Livreiro, situado na rua Riachuelo, foram 17 exemplares ao preço de $\mathrm{R} \$ 20,00$ cada um. O primeiro volume faltante, ele conseguiu adquirir em outra loja do Beco que não a da Andradas. Revelou amar tanto essa coleção que, à noite, enquanto escuta jazz, ocupa-se em restaurar a coleção objetivando tornar imperceptíveis pequenas imperfeições. Com medo de danificar a coleção, adquiriu outros exemplares destinando-os à leitura, permitindo-se assim um manuseio mais livre. Moraes (2005) revela que Mário de Andrade era um bibliófilo que, ao 
receber um exemplar autografado por um autor conhecido, costumava guardálo tal qual o recebera, sem folheá-lo. Para efetuar a leitura comprava outro exemplar do mesmo livro e esse sim era riscado, sublinhado, com observações acrescidas às margens.

Os achados de campo e a bibliografia trazem à tona a constelação de objetos que circunda o colecionador de livros como algo que revela o self que ele busca construir ou reforçar. O jazz, os autores clássicos da literatura brasileira e a coleção de livros obsessivamente cuidados - mais uma característica dos colecionadores - denotam alguém que procura se distinguir por seu alto capital cultural. Nesse caso, assim como no dos demais bibliófilos aqui descritos, o self de intelectual é construído e cuidadosamente mantido por meio das posses. Mais do que a coleção, aqui a constelação de bens fala pelo seu detentor (Douglas; Isherwood, 2004; McCracken, 1989).

Dr. Aurélio lembra que desde criança gostava de colecionar coisas, figurinhas, carrinhos e, depois de adulto, livros. Esse último objeto representa um maior dispêndio monetário, mas, segundo o referido psiquiatra, "a gente precisa ter”. Segundo Baker e Gentry (1996), quando criança nós colecionamos por diversos motivos, tais como para crescer como pessoa, por paixão, para mostrar capacidade de adquirir "mais" que os outros, para melhorar nossa identidade e para mostrar que somos únicos. Temos, então, que a substituição do objeto da coleção quando da passagem para a vida adulta não invalida algumas de suas motivações, que vêm desde a infância. Fica evidente a motivação pelo destaque pessoal e pela busca por identidade no caso dos nossos colecionadores de livros. Da mesma forma, a mudança de objeto representa uma conformação com os padrões socialmente aceitos, onde de parte de um homem não se espera que mantenha uma coleção de figuras, mas sim algo de acordo com o seu status de homem. Como bem colocam Douglas e Isherwood (2004, p. 172): "para cada status, um certo grau de consumo é considerado apropriado”.

Na Nova Roma, um cliente manifestou, certa ocasião, a sua percepção sobre alguns questionamentos feitos a quem coleciona livros. Uma das perguntas que revelou ser bastante comum é a seguinte: "Você já leu todos os livros que adquiriu?” Para essa pessoa, é curioso porque ninguém faz a mesma pergunta a um colecionador de canetas ou selos. No seu entender a coleção de livros não é para ser lida, mas simplesmente olhada, tal como os selos e as canetas que se usados implicam o desaparecimento da coleção. Nesse caso, o colecionador não obtém o objeto para ser lido, mas pela carga simbólica depo- 
sitada nele (Baudrillard, 1972). Isso nos mostra o caráter eminentemente autotélico de qualquer coleção; por mais útil que seja o objeto, ao se tornar parte de uma coleção, ele é despojado de sua função utilitária (Belk et al., 1988).

Sr. Ronaldo, outro bibliófilo que conhecemos na Nova Roma, parece pactuar com essa visão, pois, para ele, colecionar não significa ler todos os livros. Nas suas palavras, "a raridade vicia” e o colecionismo nesse caso passa a ter um certo fetiche. Acordar de madrugada e admirar as raridades que possui faz parte desse fetiche. Relatou ter um exemplar do Tronco do Ipê, de José de Alencar, datado de 1871, a raridade não se dá pela datação, mas sim pela dificuldade que se constitui encontrá-lo, a obra apresenta cinco páginas de errata.

Uma das características da coleção é que seu início não é proposital e que o colecionador somente se descobre como tal quando já está irremediavelmente imerso no universo de sua coleção (Belk et al., 1988). Mindlin (1997, p. 1516) explica como se tornou um bibliófilo e até certo ponto a sua narrativa vai ao encontro daquilo que pudemos verificar em campo na convivência com bibliófilos de Porto Alegre:

O livro exerce uma atração multiforme que vai muito além da leitura, embora esta seja um ponto de partida fundamental. Em primeiro lugar, existe a ilusão de que se vai conseguir ler mais do que na realidade se consegue. Depois vem o desejo de ter à mão o maior número possível de um autor de quem se gosta - já é o começo de uma coleção. Conseguindo o conjunto, que sempre se quer o mais completo possível, surge o interesse pelas primeiras edições, geralmente raras, e a atração pelo livro como objeto, e também como objeto de arte, em que entra a qualidade do projeto gráfico, a ilustração, a diagramação, o papel, a tipografia, a encadernação; e aí já surge a busca da raridade. Quando se chega a esse estágio, aquele que pensava em ser na vida apenas um leitor metódico, está irremediavelmente perdido. Sua relação com o livro passa a ter uma dimensão quase patológica, pois a compulsão de possuí-lo é mais ou menos irresistível (mais mais do que menos).

As emoções experimentadas pelos bibliófilos vão ao encontro daquilo que teorizou Featherstone (1995) ao referir os prazeres emocionais advindos do consumo e que remetem aos sonhos e desejos presentes no imaginário cultural relativo à aquisição de mercadorias e serviços utilizados como forma de distinção e para estabelecer vínculos e sociabilidades, atuando como marcadores de diferentes estilos de vida.

Dentre as vivências do sr. Ronaldo como bibliófilo existe o relato de uma situação em particular. Certa ocasião colocou anúncios em um jornal local de 
grande circulação, mencionando comprar livros usados e antigos. Em razão disso, certo dia, aparece em sua casa um rapaz portando um livro a ser vendido. A esposa do sr. Ronaldo cientificou o rapaz de que seu marido não se encontrava no momento e o rapaz garantiu voltar mais tarde. Ao chegar à sua residência, o sr. Ronaldo fica sabendo que se tratava do livro Menina Moça, de Bernardi Ribeiro, realmente uma raridade. Temeroso devido à incerteza sobre o retorno ou não do rapaz, o sr. Ronaldo aguardava a chance de negociar aquela obra. O rapaz volta ao local e faz a sua proposta para a venda do livro. A identificação por parte do sr. Ronaldo da utilização de papel trapo garantia a antiguidade da obra, porém, ao verificar um defeito na lombada do livro, o bibliófilo, num "ímpeto de maldade", como ele mesmo menciona, faz desse defeito o mote para a sua negociação e consegue adquirir o livro por um preço muito baixo, tão baixo que até hoje parece ter um certo remorso por ter se aproveitado do desconhecimento do vendedor em face da preciosidade que possuía.

Os critérios que definem o que é "realmente uma raridade" é domínio de um grupo restrito. Os bibliófilos fazem parte de um grupo que atribui maior ou menor valor ao objeto; eles são os conhecedores, os peritos dos critérios que fazem do livro uma raridade. Douglas e Isherwood (2004, p. 123-124) dizem que há "marcadores sociais" que delimitam o saber sobre o objeto dado:

Os bens são dotados de valor pela concordância dos outros consumidores. [...] O fluxo dos bens consumíveis deixa um sedimento que constrói a estrutura da cultura como ilhas de coral. O sedimento é o aprendido conjunto de nomes, operações a serem feitas sobre os nomes, um meio de pensar.

Se a narrativa do sr. Ronaldo ressalta a felicidade pela possibilidade de ter concretizado a sua aquisição, no caso de Moraes (2005), a narrativa evidencia a frustração decorrente da barganha incapaz de reverter a situação. Vejamos o contraponto da experiência vivida pelo sr. Ronaldo. Moraes (2005), frustrado, em sua história não consegue comprar uma primeira edição rara de um livro por conta do preço abusivo proposto pelo vendedor com quem tentou negociar em várias circunstâncias. A impossibilidade de aquisição da mercadoria desejada, no caso o livro raro, remete à identificação da carga simbólica imputada a esse bem, pois estaria dentre o rol de bens que

tendem a ser excluídos da troca, não se tolerando que permaneçam longamente na condição de mercadorias. Ao mesmo tempo, o status sagrado e a negação da troca 
e do mercado profanos podem, paradoxalmente, aumentar o valor desses objetos. Um objeto que não está disponível e "não tem preço” é mais caro e mais desejado. (Featherstone, 1995, p. 36).

No caso dos livros raros em razão de sua antiguidade, Baudrillard (1972) diz que o desejo pelo antigo busca transcender a dimensão do êxito econômico consagrando, por meio de um objeto simbólico, um êxito social. Assim, entre intelectuais e artistas: "é onde o gosto do antigo traduzirá mais a recusa (ou afiliação envergonhada) do estatuto econômico da dimensão social, uma vontade de se situar fora das classes, alimentando-se, tal intento, na reserva dos signos emblemáticos do passado anterior à produção industrial” (Baudrillard, 1972, p. 31-32). Nesse sentido, o gosto pelo antigo é a aquisição de objetos desviantes que desafiam um valor absoluto da sociedade, evidenciando o desejo de independência em relação ao mercado. Todavia, o consumo de livros raros, no caso dos bibliófilos, remete à inserção em um grupo restrito de relações e sociabilidades funcionando como ponte e cerca (Douglas; Isherwood, 2004), mas igualmente traduz a ótica do consumo cultural que não foge aos ditames do mercado.

Dos objetos, raros ou não, que são adquiridos pelos bibliófilos nos sebos porto-alegrenses, alguns têm significado especial por conter marcas do tempo, dos usuários precedentes ou dos próprios autores dos livros. Essas propriedades físicas são carregadas de elementos simbólicos capazes de transformar aquele exemplar em marcador de status e posição, potencializando as virtudes de uma determinada coleção. Assim, esses objetos seriam dotados de "pátina" (McCracken, 2003).

No caso dos livros, a pátina se inscreve de maneira acentuada por meio das capas danificadas, das páginas amareladas, riscadas, manuseadas e de outras propriedades físicas que o livro adquire à medida do seu envelhecimento. O prazer decorrente da busca pelas primeiras edições de livros antigos e consagrados, segundo dr. Aurélio, vai além do prazer da leitura, envolve o cheiro de fungo exalado pelo livro. Nesse caso, evidenciamos que os objetos com pátina estabelecem uma relação do objeto com uma época remota da própria vida do colecionador ou de um período de grande efervescência cultural-literária no Brasil ou no mundo, remetendo a "um espaço temporal fora do aqui e agora" (Almeida; Rocha, 2006, p. 13).

Dr. Aurélio diz que ao adentrar nesses espaços é como penetrar em outro mundo. Importante lembrar que os sebos estudados são convidativos a uma 
reação nostálgica. Objetos antigos são utilizados como decorativos, reconstruindo desordenadamente aspectos culturais do passado (Featherstone, 1997, p. 135-136). Dr. Aurélio, sobre os livros, diz: "eles não nos questionam, são passivos na estante, quando se quer, se vai lá e os pega, senão, eles continuam lá e não nos trazem preocupações. Outra coisa interessante nas bibliotecas é a convivência de autores, célebres autores, que hoje estão mortos e durante a vida eram inimigos”.

As observações do dr. Aurélio atinentes às questões de gênero são bastante taxativas no que concernem à incompreensão das mulheres em se tratando da compra de livros por bibliófilos. No seu dizer:

As mulheres só incomodam, acham que só se deve trabalhar e para que gastar tanto dinheiro em livro? Por isso que quando eles morrem, elas querem é se desfazer logo daquelas porcarias, que só acumula pó. Mandam para o lixo e as mais espertas vendem. As viúvas, esse é o negócio, a chave de tudo para comprar livros. Conheço um livreiro, que não vou dizer o nome, que até já se associou numa funerária para ter uma proximidade com as viúvas.

Disse conhecer uma pessoa que precisa esconder os livros adquiridos dentro de panelas para não ser descoberto por sua mulher, mas que encontra nessa estratégia uma maneira de ir montando a respectiva biblioteca. Talvez essa aversão feminina à compulsão dos maridos bibliófilos se deva àquilo que Rouveyre (2003) entende como: “efeitos nocivos imputados aos livros”. Para ele, os livros

demandam a maior parte do nosso tempo livre e de nossa atenção, conduzem nossas idéias a assuntos que não dizem nada à utilidade pública, inspiram nosso desprazer pelas ações costumeiras e pelo cotidiano da vida civil, tornam-nos preguiçosos e impedem-nos de usar nosso talento inato e o nosso conhecimento, fornecendo-nos, a qualquer instante, os assuntos inventados por outros. (Rouveyre, 2003, p. 40).

Nesse caso podemos perceber uma nítida tensão entre as intenções de imortalidade dos bibliófilos e a aversão aos livros causada em suas esposas. É possível perceber, ainda, o quão invasivo é o ato de colecionar (McIntosh; Schmeichel, 2004), fazendo com que, em alguns casos, as pessoas próximas ao colecionador desenvolvam uma atitude negativa com relação à coleção.

Na Nova Roma, reencontramos o dr. Aurélio, que nos pareceu tentar driblar a família ao comprar livros e acondicioná-los em três sacolas de super- 
mercado ao mesmo tempo em que anunciava a necessidade de fazer algumas compras no "super" antes de se dirigir para a sua residência, certamente, para disfarçar; afinal, dentre várias sacolas, os livros passariam despercebidos.

Moraes (2005) relata a história de um amigo que morreu em decorrência da frustração de não poder adquirir mais livros em razão do medo que possuía de sua esposa. Quando ele faleceu, ela não hesitou em vender a biblioteca, amealhando uma pequena fortuna. Esses relatos e mesmo evidências podem ser capturados na convivência com os bibliófilos e justificam a existência de um ex-libris feito por Haroldo Ferreira, com a inscrição: "Viúvas, alegria do sebo" (Figura 1).

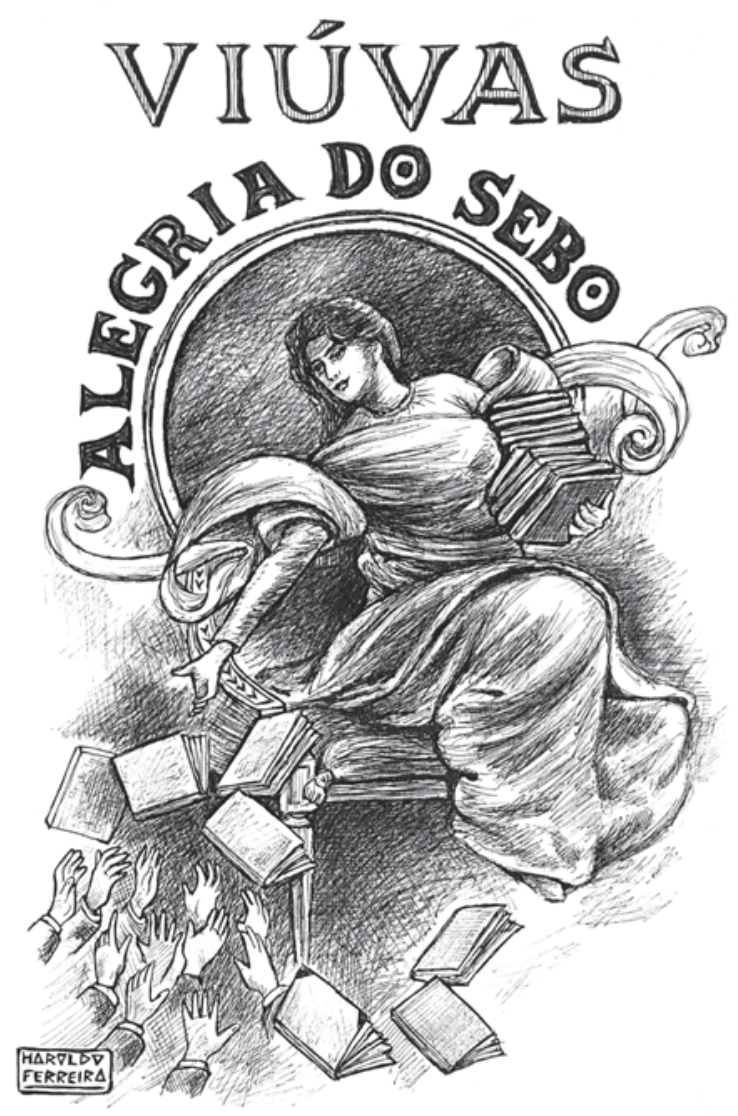

Figura l: Ex-libris de Haroldo Ferreira (2004) 
Mindlin (1997) parece ter sempre contado com o apoio da mulher, que além de leitora, também se dedicava à conservação dos livros, mediante o restauro cuidadoso das obras porventura danificadas, afora o incentivo dado no sentido de que o marido viesse a adquirir uma certa obra, mesmo que os recursos em determinado momento fossem escassos para efetuar extravagâncias.

O bibliófilo dr. Aurélio parece perceber diferenças entre os sebos. Para ele, no Beco encontra paz, ninguém o incomoda, os funcionários não o atrapalham, controlando ou oferecendo mercadorias, o atendimento é considerado excelente, rápido, destacando-se a gentileza e atenção da proprietária Neiva. Já a Livraria Nova Roma é qualificada pelo cliente como aquela que vende mais barato e que se constitui em ponto de encontro entre homens, um "clube de amigos".

Sr. Lúcio foi dono de uma livraria, porém guardava muitos livros bons para si e vendia o restante, dessa prática resultou uma pequena biblioteca pessoal de bons livros e um acúmulo de dívidas a serem pagas. Enquanto procurava livros de Castañeda, referiu que: "dizem que o homem é o melhor amigo do homem, mas eu acho que é o livro”.

Moraes (2005) chama a atenção para o fato de colecionador e livreiro serem coisas diferentes, e que quando se misturam raramente dão certo. Relatou o caso de um amigo bibliófilo que resolveu abrir uma livraria como forma de aumentar a biblioteca pessoal com um menor custo. Da mesma forma que o sr. Lúcio, o livreiro da narrativa de Moraes só disponibilizava aos clientes as obras que não lhe interessavam, os rebotalhos eram postos à venda sem sucesso, viuse então obrigado a vender a livraria antes de ir à falência. É bem possível que Moraes estivesse se referindo a Mindlin, uma vez que o primeiro deixou de herança para o segundo a sua biblioteca pessoal e o segundo ao relatar sua trajetória em livro conta que ao ser dono de uma livraria:

[...] comprei na Europa coisa de dois ou três mil volumes, de literatura geral, arte, e viagens, principalmente sobre o Brasil, com muitas edições importantes, e, quando chegavam os pacotes, Blum, eu e uma mocinha que trabalhava conosco [...] sentíamos a maior alegria. Mas quando se vendia um bom livro, era uma tristeza...! porque nós não podíamos ficar com os livros - tínhamos a obrigação moral de vendê-los, dada a contribuição do terceiro sócio. (Mindlin, 1997, p. 123-124).

Mindlin acabou se desfazendo da livraria, optando por sua biblioteca, pois chegara à conclusão que a manutenção das duas seria inviável, daí a nossa inferência com relação à narrativa de Moraes. 
Sr. Lúcio diz encontrar nos livros uma fonte de vida em momentos difíceis, a exemplo de certa ocasião quando foi demitido de seu emprego e entrou em depressão, os livros foram a terapia que o apoiou. As necessidades emocionais, supridas em parte pelos livros, fazem com que o sr. Lúcio separe a obra do autor, qualificando os livros como amigos dos homens mais do que os próprios homens, como se os primeiros não fossem fruto de uma realização humana. Rouveyre (2003) também estabelece uma distinção entre livreiros, colecionadores e homens cultos no que diz respeito à noção do que vem a ser um bom livro para cada uma das três categorias, o que de certo modo demonstra a baixa probabilidade de um livreiro conseguir se enquadrar nas duas classificações ao mesmo tempo, quais sejam, a de livreiro e colecionador. No entender do autor anteriormente referenciado, um bom livro para um livreiro é aquele que vende bem, para um colecionador é o livro raro e para o homem culto, aquela obra que lhe parece instrutiva.

Sr. Edson, professor de história, freqüenta o Beco duas ou três vezes por mês quando tem tempo livre, fica geralmente cerca de três horas "garimpando” livros nas prateleiras. Diz a princípio não ter a pretensão de comprar nada, procura apenas “alguma surpresa”. Perguntado sobre o que seria "uma surpresa”, explicou que ao abrir um livro e ler algum trecho, se defrontando com pequenas frases que remetem a construção de uma idéia interessante sobre o assunto que ele costuma trabalhar, isso tende a lhe despertar a vontade de ler o livro todo. Às vezes encontra raridades que lhe interessam, mas não tem dinheiro para comprá-las. Para ele, comprar um livro e ler é como comer, andar, ou seja, faz parte daquilo que é viver. Atualmente, sua linha de pesquisa centra-se na história do Brasil e formação econômica do Brasil. Ele acha a cidade de Porto Alegre privilegiada por ter vários sebos que julga importantes, justamente por terem obras que não se encontram mais em bibliotecas. As bibliotecas brasileiras, segundo ele, têm muita deficiência de conteúdo em determinados assuntos.

Sr. Edson comentou também que em Porto Alegre existiam muitas famílias tradicionais, estancieiros abastados, que vieram do interior do estado se estabelecer na capital. A situação econômica permitia que os filhos dessas famílias tivessem uma formação no exterior, os bacharelados, e o conseqüente acesso à cultura européia fazia com que esses cidadãos fossem dignos de reconhecimento e respeito ao retornarem ao Brasil. A formação cultural muito mais intensa no exterior também implicava posse de bibliotecas riquíssimas sobre diversos assuntos, contendo inclusive literatura estrangeira. Quando da morte dessas pessoas, as famílias costumam se desfazer das bibliotecas, vendendo- 
as para sebos, e aí, nos sebos, é possível encontrar essas obras raras, inclusive com dedicatórias de pessoas importantes. Ocorre às vezes desses livros irem parar na mão de pessoas erradas e se perderem ou não serem aproveitados da melhor maneira possível. Pessoas estrangeiras vêm até os sebos brasileiros comprar raridades em dólar e isso, para ele, também é lamentável, porque o Brasil está perdendo riqueza cultural e nem sabe. Para o professor Edson, a questão do caro e do barato no sebo deve ser contextualizada, pois o livro usado é caro para o poder aquisitivo dos brasileiros, mas ao mesmo tempo é barato se comparado com gastos empreendidos na aquisição, por parte da população, “de bobagens e futilidades”, sendo que o valor cultural do livro não tem como ser avaliado.

Os postulados do sr. Edson vão ao encontro das considerações de Moraes (2005, p. 18): “[...] graças a colecionadores particulares, muito tesouro é salvo. No Brasil então, onde a administração pública, além de ignorante é desmazelada, se não fosse o colecionador particular, o bicho, a sujeira e o clima destruiriam tudo o que o nosso passado legou". E sobre a compra em dólar: "O livro antigo é uma mercadoria internacional, seu preço é regulado em moeda forte” (Moraes, 2005, p. 31).

Sr. Aldo é um professor para quem o livro ou a leitura leva à possibilidade de abstração. Chama a atenção para o compromisso que nós, humanos, temos com o conhecimento e com a inteligência. Seu apreço para com os sebos começou em decorrência de sua família ser “uma família de leitores”, seu pai era um leitor voraz. A opção pelos sebos na época dava-se em razão dos preços serem mais acessíveis. Durante a adolescência e logo após ingressar na universidade freqüentava o sebo Aurora (existente ainda hoje, localizado na rua Marechal Floriano) e a Martins Livreiro. Referiu que o sebo configura-se como um local onde não perdemos as esperanças, isso porque, muitas vezes, lemos um livro, o emprestamos e ele não nos é devolvido, ocorre não ser reeditado e então passamos um bom tempo sem ter acesso ao mesmo, porém, um dia, em algum sebo, voltamos a reencontrá-lo. Contou ter esperado 23 anos para encontrar um determinado livro.

Pelo que nos foi possível observar a noção de raridade não é consenso entre os bibliófilos, o que pode ser raridade para um pode não ser para o outro. Mindlin (1997, p. 29-30) faz essa ressalva em sua obra:

O livro pode ser raro, por exemplo, por terem sido impressos poucos exemplares, ou por não se terem conservado os que se imprimiram, pelo interesse do texto, por 
ser uma primeira edição ou por ter uma revisão do próprio autor.[...] Mas não somente as primeiras edições são objeto de desejo. Livros com dedicatória do autor, manuscritos, folhetos, encadernações especiais, ou certas traduções, também podem ter lugar importante na biblioteca.

\section{Consideracõos finais}

Considerando que o consumo pode servir como ponte na construção de relações sociais, no momento em que o hábito de comprar e ler livros requer um conhecimento intelectual histórico e de reconhecimento de autores e valores inscritos em suas obras que motivam a leitura, esse consumo está sendo compartilhado socialmente. Isto é, trata-se de um processo social e cultural, o mesmo se dando com uma parte do universo de significados, o que acaba atribuindo também uma identidade social para os indivíduos, bibliófilos, que demandam por tais obras.

Os critérios de marcação compartilhados pelo grupo dos bibliófilos podem ser o reconhecimento do valor atribuído a um livro como raridade. A aquisição de uma obra rara é a "prova" material que o possuidor tem para justificar o simbolismo e os significados construídos culturalmente e depositados nesse objeto. A procura por uma obra para fazer parte do acervo passa a ser a busca por aquilo que os informantes denominaram de "surpresa", que remete à dimensão prazerosa do processo de consumo (Featherstone, 1995) e à busca obsessiva por completar uma coleção (Belk et al., 1988).

Partindo da idéia de que "somos o que possuímos", podemos visualizar a coleção do bibliófilo como um depósito, onde foi acumulado tempo, energia, dinheiro e conhecimento intelectual. Todos esses acúmulos assumem as características do estilo de vida do possuidor e de sua identidade social. $\mathrm{O}$ autoconceito do indivíduo está embutido no objeto que ele coleciona na medida em que revela traços do universo pessoal do colecionador. Dessa forma, a coleção se torna uma parte importante do self estendido dos colecionadores (Belk, 1988), e o consumo se mostra um instrumento privilegiado para a construção e reforço de uma identidade masculina, ligada ao conhecimento, a um alto capital cultural, à pertinência a um grupo selecionado de pessoas e à nostalgia com relação à própria vida e um período de grande produção cultural-literária no Brasil e no mundo.

Além disso, a construção e confirmação do self por intermédio dos bens, tal como se revelou nesse trabalho, nos leva a especular a respeito da impor- 
tância da cultura material para o contexto dito pós-moderno. Tendo em conta que os bens têm a propriedade de estabilizar as categorias culturais e dar sentido à vida quotidiana (Douglas; Isherwood, 2004), nos parece que eles são particularmente necessários como âncoras “ordenadoras do self” naquilo que alguns convencionaram como experiência pós-moderna, agindo de modo a contrabalançar as características de fragmentação, desordem e caos inerentes à referida condição.

A imersão no universo dos bibliófilos nos revelou, ainda, a presença de características importantes relativas à prática de colecionar (Belk et al., 1988). O "vício" da raridade e o cuidado obsessivo com os livros aparecem como importantes categorias para os bibliófilos. Ademais, os livros sofrem uma espécie de sacralização quando são incorporados a uma coleção; incorporação essa que retira também o caráter utilitário do livro, tornando a prática de colecionar algo contido em si mesmo.

A busca pela "surpresa" e pela raridade nos diferentes sebos da cidade mostrou um tipo de comércio ao mesmo tempo transacional e relacional entre livreiros, vendedores esporádicos e bibliófilos. Transacional, quando se levam em conta as práticas oportunistas de compra e venda de livros, onde o objetivo é adquirir a obra pelo preço mais barato ou vendê-la pelo preço mais caro. Nesse caso, o domínio da informação sobre o valor das obras é determinante para o (in)sucesso do vendedor ou do comprador. O caráter relacional se revela na fidelidade ao livro, mais especificamente, à categoria de produto "livros usados”, e aos sebos de uma maneira geral, capazes de serem os portadores dos significados relevantes para os bibliófilos.

Por fim, o colecionismo se revelou um comportamento situado no extremo de um contínuo, onde o consumo é não-racional e simbólico (em oposição ao racional e ao utilitário), desde o processo de tomada de decisão e compra até o uso (exibição) do produto. Como todo o comportamento extremo, a análise dos colecionadores pode nos auxiliar a visualizar mais claramente alguns processos de consumo na sociedade contemporânea, notadamente no que tange às propriedades simbólicas que os bens carregam consigo, e também na compreensão dos processos de apropriação e personalização dos bens quando da sua passagem do domínio da produção para o domínio do consumo. Nesse sentido, pesquisas futuras podem se beneficiar dos resultados aqui encontrados para proceder tais análises. 


\section{Referências}

ALMEIDA, Victor.; ROCHA, Ângela. O efeito pátina nas marcas: uma reflexão sobre a inscrição de signos conotativos da passagem do tempo nos objetos de consumo. In: ENCONTRO DE MARKETING, 2., 2006, Rio de Janeiro. Anais... Rio de Janeiro: Anpad, 2006. p. 1-16. 1 CD-ROM.

BAKER, Stacey; GENTRY, James. Kids as collectors: a phenomenological study of first and fifth graders. Advances in Consumer Research. Ed. Kim P. Corfman and John G. Lynch Jr. Provo: Association for Consumer Research, v. 23, p. 132-137, 1996.

BARBOSA, Lívia. Sociedade de consumo. Rio de Janeiro: Jorge Zahar, 2004.

BAUDRILLARD, Jean. Para uma crítica de economia política do signo. Lisboa: Edições 70, 1972.

BELK, Russel. Possessions and extended self. Journal of Consumer Research, Chicago: The University of Chicago Press, v. 15, n. 2, p. 139-168, September 1988.

BELK, Russel et al. Collectors and collecting. Advances in Consumer Research. Ed. Micheal J. Houston. Provo: Association for Consumer Research, v. 15, p. 548-553, 1988.

BOURDIEU, Pierre. La distinction: critique sociale du jugement. Paris: Minuit, 1979.

CAMPBELL, Colin. A ética romântica e o espírito do consumismo moderno. Rio de Janeiro: Rocco, 2001.

CASTILHOS, Rodrigoet al. Self estendido e posse no local de trabalho: uma réplica no contexto brasileiro. In: ENCONTRO DE MARKETING, 2., 2006, Rio de Janeiro. Anais... Rio de Janeiro: Anpad, 2006. 1 CD-ROM.

CLIFFORD, James. A experiência etnográfica: antropologia e literatura no século XX. Rio de Janeiro: UFRJ, 1998. 
DOUGLAS, Mary; ISHERWOOD, Baron. O mundo dos bens: para uma antropologia do Consumo. Rio de Janeiro: UFRJ, 2004.

FEATHERSTONE, Mike. Cultura de consumo e pós-modernismo. São Paulo: Studio Nobel, 1995.

FEATHERSTONE, Mike. O desmanche da cultura: globalização, pósmodernismo e identidade. São Paulo: Studio Nobel: Sesc, 1997.

JAIME, Jr. Pedro. Pesquisa em organizações: por uma abordagem etnográfica. Civitas, Porto Alegre, v. 3, n. 2, p. 435-456, jul./dez. 2003.

HILL, Ronald; STAMEY, Mark. The homeless in America: an examination of possession and consumption behaviors. Journal of Consumer Research, Chicago: The University of Chicago Press, v. 17, n. 3, p. 303-321, December 1990.

MATOSO, Cecília; ROCHA, Ângela. Significados associados às estratégias para solução de problemas financeiros dos consumidores pobres. In: ENCONTRO ANUAL NACIONAL DA ASSOCIAÇÃO DOS PROGRAMAS DE PÓS-GRADUAÇÃO EM ADMINISTRAÇÃO, 29., 2005, Brasília. Anais... Brasília: Anpad, 2005. 1 CD-ROM.

McCRACKEN, Grant. Homeyness: a cultural account of one constellation of consumer goods and meanings. Interpretive Consumer Research. Ed. Elizabeth C. Hirschman. Provo: Association for Consumer Research, v. 16, p. 168-183, 1989.

McCRACKEN, Grant. Cultura e consumo: novas abordagens ao caráter simbólico dos bens e das atividades de consumo. Rio de Janeiro: Mauad, 2003.

McINTOSH, William; SCHMEICHEL, Brandon. Collectors and collecting: a social psychological perspective. Leisure Sciences, Oxfordshire: Taylor \& Francis, v. 26, n. 1, p. 85-97, Jan./Mar. 2004.

MINDLIN, José. Uma vida entre livros: reencontros com o tempo. São Paulo: Edusp: Companhia das Letras, 1997.

MORAES, Rubens Borba de. O bibliófilo aprendiz. 4 ed. Rio de Janeiro: Casa da Palavra, 2005. 
ROCHA, E.; BARROS, C.; PEREIRA, C. Perspectivas do método etnográfico em marketing: consumo, comunicação e netnografia. In: ENCONTRO ANUAL NACIONAL DA ASSOCIAÇÃO DOS PROGRAMAS DE PÓSGRADUAÇÃO EM ADMINISTRAÇÃO, 29., 2005, Brasília. Anais... Brasília: Anpad, 2005. 1 CD-ROM.

ROUVEYRE, Edouard. Dos livros. Rio de Janeiro: Casa da Palavra, 2003.

SCHOUTEN, John W.; McALEXANDER. Subcultures of consumption: ethnography of the new bikers. Journal of Consumer Research, Chicago: The University of Chicago Press, v. 22, n. 1, p. 43-61, June 1995.

SLATER, Don. Consumer culture and modernity. Oxford: Blackwell, 1997.

TIAN, Kelly and BELK, Russel. Extended Self and Possessions in the Workplace. Journal of Consumer Research, Chicago: The University of Chicago Press, v. 32, n. 2, p. 297-310, December 2005. 